\title{
Analisa Penurunan Daya yang Dihasilkan Mesin Bantu Guna Meningkatkan Operasional Kapal di MT. Dewi Maeswara
}

\author{
M. Ridwan ${ }^{1}$, Diah Zakiah ${ }^{2}$, Ardiansyah ${ }^{3}$ \\ ${ }^{1,2,3}$ Prodi Teknika \\ Sekolah Tinggi Ilmu Pelayaran, Jakarta \\ Jl. Marunda Makmur No. 1 Cilincing, Jakarta Utara. Jakarta 14150
}

\begin{abstract}
Abstrak
Mesin bantu memiliki peran yang sangat besar dalam pengoperasian kapal. Masalah yang sering muncul pada mesin bantu adalah tidak tepatnya waktu pengabutan bahan bakar oleh fuel injection pump dan goresan pada jarum tekan injector (plunger). Tujuan dilakukan penelitian ini yaitu untuk mengetahui penyebab tidak tepatnya waktu pengabutan bahan bakar ke dalam ruang bakar mesin bantu dan menemukan penyebab terjadinya goresan pada jarum tekan injector (plunger). Metode yang digunakan adalah deskriptif kualitatif. Dari hasil penelitian diperoleh kesimpulan bahwa terlambatnya waktu pengabutan bahan bakar pada diesel generator nomor 2 disebabkan karena rendahnya suhu gas buang pada silinder nomor 1 dan 2. Hasil pengambilan tekanan Pmax menunjukkan tekanan yang tidak mencapai titik maksimal pada silinder nomor 1 dan 2 atau Pmax nya terlalu rendah. Permasalahan pada fuel injektor (goresan pada jarum tekan atau plunger) disebabkan karena perbedaan temperatur gas buang yang sangat signifikan pada diesel generator nomor 2, termometer pada gas buang silinder nomor 4 dan 5 menunjukan angka diatas rata-rata sedangkan pada silinder lainnya yaitu nomor 1,2,3 dan 6 temperatur terlihat normal yaitu berkisar antara 3500C - 3700C.
\end{abstract}

Copyright $(2020$, Prosiding Seminar Pelayaran dan Riset Terapan

Kata Kunci: penurunan, daya, mesin bantu

Permalink/DOI : https://doi.org/10.36101/pcsa.v2i1.138

\section{PENDAHULAN}

Mesin bantu (auxiliary engine) merupakan sarana bantu utama untuk kinerja mesin induk. Salah satu contohnya adalah mesin diesel penggerak alat pembangkit tenaga listrik yang dipergunakan oleh pesawat-pesawat bantu serta peralatan elektrik lainnya di kapal. Hal ini sangat dibutuhkan dalam pengoperasian, sehingga kapal dapat bekerja seefisien mungkin untuk menghemat waktu dan energi dalam proses pelaksanaan olah gerak, proses bongkar muat, maupun aktifitas lainnya yang berhubungan dengan pengoperasian kapal.

Untuk menjaga kondisi permesinan baik mesin utama maupun mesin bantu, perawatan dan pemeriksaan secara rutin merupakan tindakan pencegahan agar mesin tetap terjaga kondisinya atau tidak cepat rusak. Apabila permesinan rusak akan menghambat pengoperasian kapal dan perusahaan akan mengalami banyak kerugian, demikian pula dengan masyarakat sebagai konsumen membutuhkan barang hasil produksi.

Kelancaran mesin bantu didukung pula dengan kelancaran dan sempurnanya pengabutan bahan bakar terutama dalam menjaga keefektifan kinerja mesin bantu. Perawatan dan perbaikan yang dilakukan secara tidak rutin dan tidak sesuai dengan manual book akan mengakibatkan kotornya fuel injection pump sehingga waktu pengabutan bahan bakar tidak tepat serta kebocoran kompresi bahan bakar pada alat pengabut mengakibatkan tidak sempurnanya pengabutan bahan bakar ke dalam ruang bakar, seperti yang dialami peneliti pada saat praktek di atas kapal.

Pada saat menjalankan mesin bantu untuk melakukan proses bongkar muat muatan, mesin bantu (auxiliary engine) tersebut tidak dapat bekerja dengan maksimal sehingga daya yang dihasilkan turun. Melihat kejadian tersebut, masinis jaga melakukan pemeriksaan pada mesin bantu dengan mengikuti instruksi dari buku manual. Dalam mengikuti beberapa petunjuk di dalam buku manual, masisnis jaga dan peneliti melakukan pengecekan langsung pada bagianbagian motor bantu sesuai dengan ketentuan yang ada.

Pembakaran pada mesin dapat terjadi berdasarkan prinsip segitiga api yaitu adanya 
bahan bakar, udara, dan panas. Apabila komposisi dari ketiga unsur tersebut tidak pas, maka pembakaran yang sempurna tidak dapat terjadi. Dan akan memberikan dampak pada kinerja mesin bantu. Dari penjelasan tersebut, dapat ditemukan masalah sebagai berikut:

1. Tidak tepatnya waktu pengabutan bahan bakar ke dalam ruang bakar oleh fuel injection pump.

2. Terdapat goresan pada jarum tekan injector (plunger).

3. Macetnya fuel rack pada fuel injection pump akibat kurangnya pelumasan.

4. Jenis bahan bakar tidak sesuai dengan rekomendasi buku manual.

5. Kurangnya perawatan pada sistem pengabutan bahan bakar tersebut.

6. Fuel injection pump kotor sehingga tidak berfungsi dengan baik

7. Proses pembakaran bahan bakar didalam ruang pembakaran tidak sempurna.

Berdasarkan uraian yang telah disampaikan dalam latar belakang, peneliti merumuskan permasalahan sebagai berikut:

1. Apa yang mengakibatkan tidak tepatnya waktu pengabutan bahan bakar oleh fuel injection pump?

2. Apa penyebab goresan pada jarum tekan injector (plunger)?

Kemudian tujuan dilaksanakannya penelitian ini yaitu:

1. Untuk mengetahui penyebab tidak tepatnya waktu pengabutan bahan bakar ke dalam ruang bakar mesin bantu.

2. Untuk menemukan penyebab terjadinya goresan pada jarum tekan injector (plunger).

\section{METODE}

Metode Pendekatan yang digunakan dalam penelitian ini adalah metode pendekatan deskriptif kualitatif. Dalam memperoleh data peneliti menggunakan teknik pengumpulan data berupa observasi. Observasi adalah pengumpulan data berupa informasi berdasarkan pengamatan langsung oleh peneliti di MT. Dewi Maeswara.

\section{HASIL DAN PEMBAHASAN}

Peranan diesel generator sangatlah penting dalam mendukung kinerja operasional kapal yang berfungsi menghasilkan daya atau energi listrik. Energi listrik yang dihasilkan berguna sebagai pendukung mesin-mesin bantu maupun mesin induk di atas kapal. Maka dari itu diperlukan perbaikan dan perawatan secara baik dan efisien guna menghindari masalah-masalah pada diesel generator yang muncul di atas kapal. Diesel generator di kapal MT. DEWI MAESWARA berjumlah 4 (empat) unit, 3 (tiga) diantaranya adalah main diesel generator sedangkan sisanya adalah emergency diesel generator.

Berikut adalah beberapa temuan saat peneliti observasi di MT. DEWI MAESWARA terutama yang menyangkut masalah perawatan dan perbaikan terhadap diesel generator di atas kapal.

1. Timing Injection (waktu pengabutan) yang tidak tepat

Pada tanggal 04 Januari 2018 saat jam jaga masinis 3, kapal akan memasuki SPM (Single Point Mooring) Pertamina Cilacap, Indonesia untuk proses bongkar muatan dari terminal pengisian SPM ARAMCO Rastanurah, Arab Saudi. Pada pukul 14.15 WIB saat melakukan persiapan operasional bongkar muatan diesel generator nomor 1,2 dan 3 dioperasikan. Akan tetapi pada diesel generator nomor 2 tidak mampu menghasilkan daya seperti halnya generator nomor 1 dan 3 .

Hal ini ditunjukan dengan rendahnya suhu gas buang $\left(320^{\circ} \mathrm{C}-324^{\circ} \mathrm{C}\right.$ pada silinder nomor 1 dan 2) setelah dilakukannya load sharing pada tiap diesel generator. Berdasarkan data dari buku manual pada saat diesel generator diberi beban $100 \%$ suhu normal tiap silinder adalah berkisar $350^{\circ} \mathrm{C}-370^{\circ} \mathrm{C}$ dan deviasi maksimum setiap silinder adalah $10 \%$ dari suhu maksimum atau sekitar $35^{\circ} \mathrm{C}$. Masinis 3 langsung melakukan pengecekan pada diesel generator nomor 2, mengecek suplai dan tekanan bahan bakar namun tidak ada yang salah dengan hal itu. Semua tekanan dipastikan normal. Kemudian masinis 3 membuka cover depan mesin mengecek bagian rack pada fuel injection pump dan melumasinya dengan minyak pelumas. Setelah dirasa cukup, masinis 3 kembali mengamati suhu gas buang dan hasilnya tetap rendah, terutama pada silinder nomor 1 dan 2. Masinis 3 mengambil keputusan untuk mengecek takanan Pmax dan mengambil diagramnya. Alat ukur atau Pmax indicator dipasangkan pada indicator cock tiap silinder secara bergantian. Hasilnya pada silinder nomor 1 dan 2 tekanan Pmax nya terlalu rendah (berkisar 16.6 Mpa dan 16.3 Mpa) dibandingkan dengan silinder lainnnya (berkisar $18 \mathrm{Mpa}$ - $19 \mathrm{Mpa}$ ).

Berikut adalah data temperatur dan tekanan Pmax yang diambil pada saat terjadi permasalahan pada diesel generator nomor 2 .

Tabel 1. Parameter Suhu dan Tekanan Diesel Generator No. 2

\begin{tabular}{|l|c|c|c|c|c|c|}
\hline PARAVETERS UNITS & 1 & $\mathbf{2}$ & $\mathbf{3}$ & $\mathbf{4}$ & $\mathbf{5}$ & $\mathbf{6}$ \\
\hline Pmax Mpa & 16.6 & 16.3 & 18.8 & 18.6 & 18.7 & 18.5 \\
\hline Exhaust Gas Temp. ${ }^{\circ} \mathrm{C}$ & 320 & 324 & 362 & 360 & 358 & 365 \\
\hline Fuel Rack Position & 26 & 26 & 26 & 26 & 26 & 26 \\
\hline JCW Outlet Temp. $^{\circ} \mathrm{C}$ & 81 & 80 & 80 & 80 & 79 & 80 \\
\hline
\end{tabular}


Berikut adalah gambar tabel data Pmax yang diambil dari manual book.

Tabel 2. Data Pmax berdasarkan manual book

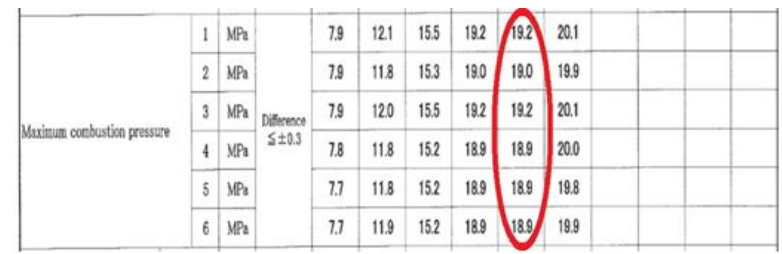

Dari hasil pengamatan, dapat dilihat bahwa temperatur gas buang dan tekanan Pmax pada silinder no. 1 dan 2 adalah rendah atau dibawah rata-rata. Kemudian Masinis 3 melapor dan berkonsultasi kepada masinis 2 perihal keputusan apa yang akan diambil terhadap indikasi yang ada karena tidak bisa melakukan overhoul sebab membutuhkan waktu yang cukup lama sedangkan proses bongkar muatan akan dilakukan.

Akhirnya diambil keputusan untuk menjalankan diesel generator tetapi bebannya dikurangi dengan cara memberhentikan beberapa permesinan. Setelah proses bongkar muatan selesai Masinis 3 membuka cover fuel injection pump silinder nomor 1 dan 2 pada diesel generator nomor 2 untuk memastikan masalah pada waktu penginjeksian bahan bakar.

Dengan melihat posisi cam knock dengan posisi derajat pada flywheel ditemukan keterlambatan 4 derajat dari yang seharusnya. Berdasarkan data dari buku manual waktu pengabutan normal adalah 150 sebelum TMA sedangkan pada diesel generator ditemukan waktu pengabutan pada posisi 110 sebelum TMA. Setelah itu Masinis 3 dibantu oleh wiper, oiler dan kadet mesin melakukan overhoul pada fuel oil injection pump untuk membersihkan dan megatur kembali waktu pengabutan bahan bakar atau timing injection pada kedua silinder.

\section{Goresan pada jarum tekan injector (plunger)}

Pada tanggal 20 Febuari 2018 pukul 10.00 LT saat rute pelayaran dari Cilacap ke Fujairah posisi kapal berada di Samudera Hindia Oiler jaga (08.00-12.00) yang mengambil jurnal menemukan perbedaan temperatur gas buang yang sangat signifikan pada diesel generator nomor 2 . Termometer pada gas buang silinder nomor 4 dan 5 menunjukan temperature yang tinggi, sedangkan pada silinder lainnya yaitu nomor 1, 2, 3 dan 6 temperatur terlihat normal (lihat lampiran 4).

Oiler jaga kemudian melaporkannya kepada masinis jaga yaitu Masinis 4. Masinis 4 mengambil tindakan untuk menghentikan diesel generator nomor 2 dan digantikan dengan diesel generator nomor 3. Pada saat serah terima jaga dengan Masinis 3 (12.00-16.00), Masinis 4 melaporkan temuan tersebut kepada Masinis 3, dan Masinis 3 memutuskan untuk melakukan pengecekan pada diesel generator nomor 2, dengan membuka dan memeriksa kedua fuel injektor tadi ditemukan adanya goresan pada jarum tekan fuel injector (plunger).

Setelah kedua fuel injektor itu dilakukan perbaikan dan dilakukan pengetesan ulang serta disetel pada tekanan pengabutan bahan bakar mendekati $320 \mathrm{~kg} / \mathrm{cm} 2$ (lihat lampiran 5), agar dapat dipasang kembali pada kedudukannya di cylinder head diesel generator, sehingga diesel generator nomor 2 dapat ditempatkan pada posisi standby atau dioperasikan. Jika terjadi masalah pada diesel generator lainnya diesel generator nomor 2 dapat dijalankan dengan normal untuk medukung kelancaran operasional kapal.

Berdasarkan data yang diuraikan diatas, selanjutnya peneliti menganalisa masalah dengan hasil sebagai berikut :

1. Timing Injection (waktu pengabutan) yang tidak tepat

Sistem bahan bakar pada mesin terdapat beberapa bagian pokok yang menyalurkan bahan bakar mulai dari tangki hingga ke dalam silinder mesin. Bagian pokok tersebut digambarkan dalam diagram berikut:

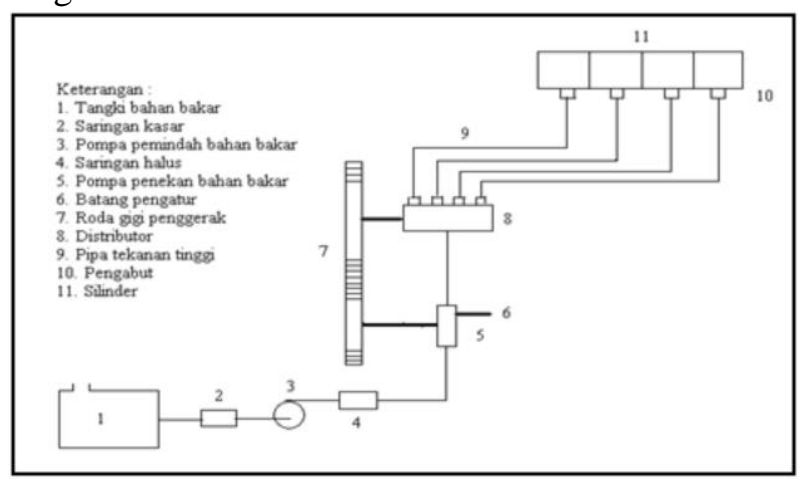

Gambar 1. Diagram jalur bahan bakar

Fuel injection pump berhubungan langsung dengan mesin. Fungsi dari fuel injection pump adalah menaikkan tekanan bahan bakar yang masuk ke dalam silinder melalui nozzle pada fuel injection valve sehingga bahan bakar tersebut berubah bentuk menjadi kabut. Dengan perubahan wujud dari cairan menjadi kabut akan mempermudah penyalaan api pada saat proses pembakaran. Pada kasus yang telah disebutkan di atas, waktu pengabutan bahan bakar tidak tepat, sehingga tekanan yang ada didalam ruang bakar tidak mencapai titik maksimal, dan temperatur gas buang pada kedua silinder berada dibawah ratarata. Waktu penyemprotan bahan bakar diatur oleh fuel cam yang tersambung dengan poros. 


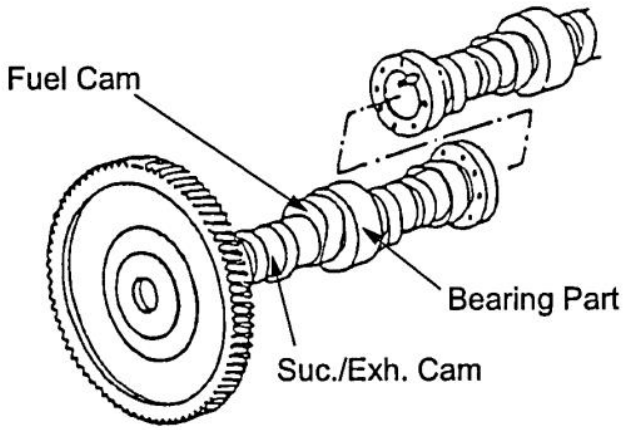

Gambar 2. Fuel cam pada poros mesin

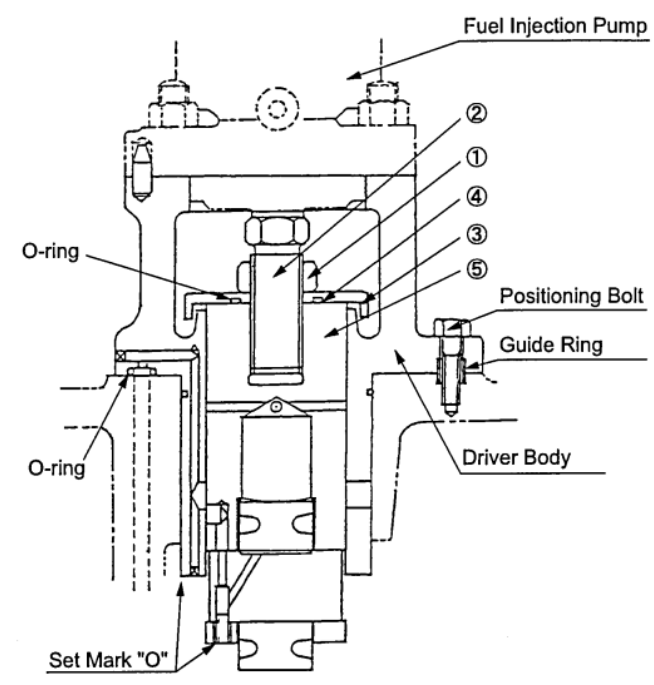

Gambar 3. Fuel injection pump driver

Fuel cam akan mendorong fuel injection pump driver sehingga tekanan bahan bakar yang masuk akan tinggi. Akibat tekanan yang tinggi tersebut maka bahan bakar yang keluar melalui fuel injection valve akan bergesekan dengan nozzle sehingga berubah menjadi kabut.

Waktu penyemprotan diatur sedemikian rupa agar bahan bakar yang disemprotkan tepat sesuai dengan gerakan piston dalam silinder. Karena diesel generator ini menggunakan mesin 4-tak, maka urutan prosesnya adalah hisap - kompresipembakaran/usaha-buang. Selama proses tersebut telah terjadi putaran sebanyak 2 kali pada crank shaft.

Berikut penjelasan dari langkah-langkah pada mesin diesel 4 tak :

a. Langkah 1 (Hisap)

Pada langkah ini piston bergerak dari TMA (titik mati atas) menuju TMB (titik mati bawah). Katup hisap terbuka sehingga akibat kevakuman yang terjadi dari ekspansi volume pada ruang bakar maka udara dari luar dapat masuk ke dalam ruang bakar melalui katup hisap yang terbuka. Pada motor bakar yang dilengkapi dengan turbocharger maka udara yang masuk ke ruang bakar akan lebih banyak lagi dikarenakan adanya dorongan dari sisi tekan compressor wheel pada turbocharger.

\section{b. Langkah 2 (Kompresi)}

Setelah piston mencapai TMB maka arah piston akan berbalik menuju kembali ke TMA, hanya saja pada langkah ini tidak ada katup yang membuka. Sebagai akibat dari mengecilnya volume ruang bakar maka udara yang ada di dalam ruang bakar menjadi terkompresi. Dengan kompresi rasio yang berkisar antara 19:1 sampai 23:1 maka pengkompresian udara pada ruang bakar akan menghasilkan panas kompresi (heat compression) yang tinggi (kurang lebih berkisar $\left.1000^{\circ} \mathrm{F}\right)$.

Beberapa derajat sebelum piston mencapai TMA bahan bakar diinjeksikan melalui nozzle ke dalam ruang bakar, penginjeksiannya harus menggunakan tekanan yang tinggi sehingga bahan bakar yang di semprotkan ke dalam ruang bakar berubah menjadi butiran-butiran cairan yang sangat halus seperti kabut. Pada saat bahan bakar disemprotkan maka campuran antara bahan bakar dan udara di dalam ruang bakar mulai terbakar akibat terkena panas yang dihasilkan oleh heat compression.

c. Langkah 3 (Pembakaran + Usaha)

Proses pembakaran campuran bahan bakar dan udara terus berlangsung sampai piston mencapai TMA dan selanjutnya kembali berubah arah kembali menuju TMB. Pada posisi 150 sebelum TMA, nozzle menyemprotkan bahan bakar. Setelah melewati TMA maka pembakaran yang terjadi telah sempurna sehingga dihasilkan ledakan yang tekanan ekspansinya memaksa piston untuk terus bergerak menuju TMB.

d. Langkah 4 (Pembuangan atau Pembilasan)

Setelah energi ledakan panas pada langkah usaha telah berubah bentuk menjadi energi mekanis maka sisa proses pembakaran yang ada harus dibuang. Proses ini terjadi ketika piston bergerak dari TMA menuju TMB dengan kondisi katup buang membuka. Gas sisa hasil pembakaran di dorong keluar oleh piston melalui katup buang dan masuk ke dalam mufler gas kemudian dimanfaatkan untuk memutarkan sudu-sudu turbin pada turbin wheel.

Jika dilihat dari penjelasan di atas, waktu penyemprotan bahan bakar oleh fuel injection pump yang diteruskan oleh fuel injection valve adalah sekitar 150 sebelum piston mencapai TMA. Namun akibat penyumbatan oleh kotoran yang berasal dari bahan bakar yang mengendap maka, penyemprotan bahan bakar menjadi tidak maksimal. Hal ini telah dibuktikan pada saat masinis 3 mencoba meng-overhaul fuel injection 
pump yang akhirnya diketahui dalam kondisi kotor.

\section{Goresan pada jarum tekan injector (plunger)}

Goresan pada jarum pengabut injector yang menyebabkan tidak sempurnanya pengabutan pada mesin bantu generator dapat disebabkan oleh:

a. Bahan bakar tidak sesuai dengan spesifikasi

Kesalahan penerimaan bahan bakar pada saat bunkering karena pihak kapal tetap menerima suplai bahan bakar meskipun spesifikasinya tidak sesuai dengan rekomendasi. Spesifikasi bahan bakar yang digunakan harus memperhatikan halhal seperti viskositas, berat jenis dan kadar aspal dalam bahan bakar, kadar vanadium, aluminium, residu karbon, air, dan sulfur. Kotoran pada bahan bakar biasanya berasal dari residu karbon yang dikandung dalam bahan bakar.

Tidak hanya berasal dari residu karbon, endapan kotoran juga berasal dari kapal tanker yang memuat MFO dari pihak bunker supplier serta sisa-sisa MFO yang dingin dan mengeras mengingat MFO adalah bahan bakar yang sifatnya sangat kental.

Jenis MFO yang digunakan di atas kapal adalah MFO 380. Perbedaan spesifikasi bahan bakar yang digunakan dapat menimbulkan masalah pada sistem pengabutan bahan bakar. Perbedaan terletak pada nilai residu karbon, alumunium dan sillica, kadar arang (ash content), dan vanadium. Batas residu karbon pada rekomendasi mesin adalah $18 \% \mathrm{~m} / \mathrm{m}$ sedangkan pada MFO 380 yang diterima pada bunkering adalah $22 \% \mathrm{~m} / \mathrm{m}$, kadar arang pada rekomendasi mesin adalah $0.1 \% \mathrm{~m} / \mathrm{m}$ sedangkan pada MFO 380 adalah $0.15 \% \mathrm{~m} / \mathrm{m}$. Kadar alumunium pada MFO 380 adalah 80 $\mathrm{mg} / \mathrm{kg}$ sedangkan yang direkomendasikan adalah $60 \mathrm{mg} / \mathrm{kg}$ serta rekomendasi kadar vanadium adalah $350 \mathrm{mg} / \mathrm{kg}$ sedangkan kadar pada MFO 380 adalah $600 \mathrm{mg} / \mathrm{kg}$.

Perbedaan spesifikasi yang signifikan ini serta endapan kotoran dapat menimbulkan banyak kotoran dan sisa-sisa pembakaran yang dapat menyebabkan kerusakan atau goresan pada jarum injector (plunger). Goresan atau baret pada jarum injector dapat menyebabkan turunnya tekanan pengabutan bahan bakar ke dalam ruang bakar. Hal ini disebabkan oleh lolosnya kompresi bahan bakar yang dilakukan oleh plunger melalui goresan atau baret pada sisi plunger.

b. Metode perawatan dan perbaikan yang

kurang tepat

Berdasarkan pengamatan peneliti dalam menentukan metode perawatan dan perbaikan yang telah direncanakan kurang tepat serta sering tertunda. Hal ini berakibat adanya gangguan pada mesin bantu generator yang disebabkan kerusakan pada alat pengabut injector sehingga kinerja mesin bantu tidak maksimal serta pengoperasian kapal tidak optimal. Seharusnya dalam penentuan metode perawatan dan perbaikan yang akan direncanakan disesuaikan dengan jam kerja mesin tersebut tanpa menunggu timbulnya kerusakan.

Untuk itu perlu dibuat suatu rencana perawatan dan perbaikan yang dilakukan sesuai jadwal serta penggunaan bahan bakar yang sesuai dengan rekomendasi yang telah ditentukan maker. Dengan demikian dapat menekan biaya pengeluaran dan juga memperkecil beban kerja dari pelaksanaan pengerjaan perbaikan.

Bila alat pengabut injector dilakukan perawatan dengan baik, maka kerja dari injector akan maksimal dan operasional mesin dapat bekerja lebih maksimal. Sebaliknya bila kurang mendapatkan perawatan yang baik akan terjadi gangguan atau kerusakan. Oleh karena itu diperlukan suatu perawatan yang tepat yang berdasarkan antara lain:

1) Perencanaan

Perencanaan perawatan dan perbaikan dapat berdasarkan buku petunjuk mesin bantu generator yang dibuat suatu perencanaan rutin dan dimasukan dalam suatu sistem, yaitu pencatatan dari sejak awal sampai akhir pekerjaan, dengan demikian setiap pekerjaan perawatan yang masih diragukan dapat diketahui lebih dini.

2) Pelaksanaan

Dalam pekerjaan perawatan dan perbaikan, semua bagian harus segera dimonitor untuk mencegah kerusakan yang lebih besar lagi dan pada waktu-waktu tertentu bagian-bagian tersebut harus ditangani secara baik.

Berdasarkan fakta-fakta dan kejadian-kejadian yang telah dianalisa oleh peneliti, maka diketahui bahwa kendala yang terjadi pada diesel generator di kapal MT. DEWI MAESWARA disebabkan oleh beberapa hal yaitu fuel injection pump yang kotor dan goresan pada jarum fuel injector (plunger). Sehubungan dengan kendala yang ditemukan pada diesel generator maka diuraikan beberapa alternatif pemecahan masalah seperti di bawah ini:

1. Timing Injection atau waktu pengabutan yang tidak tepat

Upaya-upaya yang dapat dilakukan adalah sebagai berikut:

a. Melakukan overhaul pada fuel injection pump untuk membersihkan bagian-bagian yang kotor serta mengganti komponen yang rusak

Adapun langkah-langkah dalam membersihkan fuel injection pump 
1.Cek apakah pegas pada pressure equalizing valve (13) masih dalam kondisi bagus atau tidak.

2.Cek apakah permukaan pada badan pressure equalizing valve (17) dan barrel (16) terbebas dari tekanan oleh bahan bakar.

3. Cek endapan kotoran pada plunger.

4.Jika ujung deflector (C) terlah terkorosi, maka harus diganti.

5. Ganti semua o-ring dengan yang baru

6. Bersihkan lubang barrel dan lubang pinion lube oil pada badan pompa.

7.Bersihkan semua bagian dari minyak bahan bakar yang mengeras dengan menggunakan minyak ringan seperti solar atau M.D.O (Marine Diesel Oil)

8.Pastikan plunger dan barrel terbebas dari lecet dan goresan yang dapat mengakibatkan turunnya tekanan

b. Mengatur ketebalan shim pada fuel injection pump untuk mendapatkan derajat pengabutan yang tepat

Mengatur derajat timing injction pada fuel injection pump dapat dilakukan dengan cara mengatur ketebalan shimnya. Penambahan atau pengurangan ketebalan shim dilakukan untuk memajukan atau memundurkan waktu pengabutan sesuai dengan ketentuan dari instruction manual book.

Derajat waktu pengabutan bahan bakar dapat dilihat pada derajat putaran mesin yang ada pada flywheel atau roda gila. Berdasarkan instruksi dari buku manual ketentuan ketebalan shim standar adalah $0.5 \mathrm{~mm}$. Akan tetapi untuk menyesuaikan dengan waktu derajat pengabutan yaitu 150 maka bisa dilakukan penambahan atau pengurangan ketebalan shim. Sehingga pada saat cam knock menyentuh roller pada high pressure fuel injection pump posisinya tepat pada saat 150 sebelum piston mencapai titik mati atas (TMA).

c. Membersihkan saluran pipa bahan bakar (fuel oil pipe) pada fuel injection pump

Langkah-langkah membersihkan saluran pipa bahan bakar (fuel oil pipe) adalah sebagai berikut:

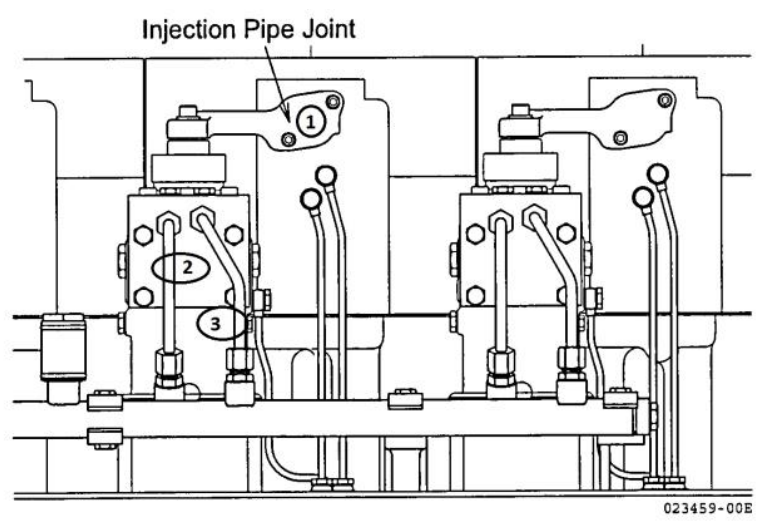

Gambar 4. Fuel injection pump dilihat dari depan
1) Lepaskan baut yang mengikat injection pipe joint (1)

2) Cek packing yang menempel pada injection pipe joint tersebut. jika kondisinya rusak, maka harus diganti.

3) Lepas pipa pada nomor 2 dan nomor 3 dengan menggunakan kunci pas secara perlahan.

4) Perhatikan tiap-tiap ujung pipa yang berbentuk bola tersebut. Jika kondisinya cacat seperti pecah atau bengkok maka dapat mengakibatkan kebocoran bahan bakar.

5) Bersihkan semua saluran fuel oil pipe dari bahan bakar yang telah mengeras menggunakan minyak ringan seperti solar atau MDO (Marine Diesel Oil) serta menggunakan kawat dan angin untuk flushing.

2. Goresan pada jarum tekan injector (plunger) Langkah-langkah dalam membongkar fuel injector untuk melakukan perawatan dan perbaikan adalah sebagai berikut :

a. Melakukan lapping pada jarum tekan injector

1) Siapkan peralatan di bawah ini :
a) Tracker
b) Baut
c) Mur
d) Kunci pas ukuran $8 \mathrm{~mm}$ dan $6 \mathrm{~mm}$

2) Lepaskan baut penjepit (5) pada fuel injection pipe joint (4) dengan menggunakan kunci pas. Lepas juga baut di sisi fuel injection pump.

3) Lepas mur pengikat pada fuel valve.

4) Kendorkan baut (6) pada fuel injection pipe (7), dan lepaskan bersama dengan fuel injection pipe.

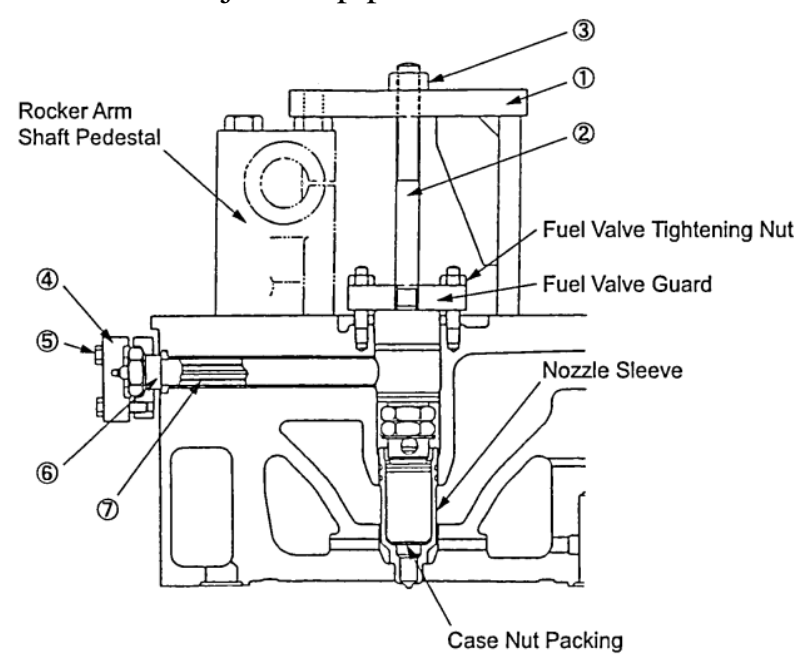

Gambar 5. Fuel Injection Valve

5) Perlakukan pipa injeksi dengan hati-hati karena kebocoran minyak terjadi jika permukaan bola pada kedua ujung pipa injeksi bahan bakar menjadi cacat.

6) Putar baut penarik (2) ke fuel valve guard. 
7) Kencangkan mur (3) untuk menarik keluar fuel valve.

8) Keluarkan case nut packing pada ujung fuel valve.

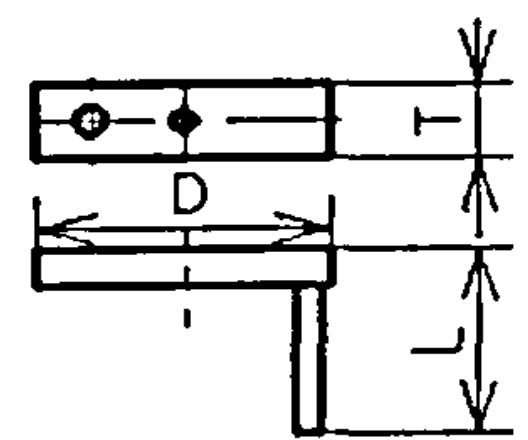

Gambar 6. Special tools untuk fuel injection valve

9) Lepas dan bersihkan semua bagian injector dari kotoran dengan menggunakan solar

10)Keluarkan jarum nosel dari badan nosel bersihkan dan cek goresan yang ada, lapping menggunakan braso jika masih dalam batas toleransi.

11)Pasang kembali semua bagian injector seperti semula dan lakukan pengetesan dengan alat tes injector

b. Mengganti jarum tekan (plunger) dan rumah jarum tekan injector

Jarum tekan injector dengan goresan yang telah melebihi toleransi tidak dapat digunakan. Mengganti jarum dan rumah jarum tekan harus dilakukan untuk mendapatkan tekanan pengabutan bahan bakar yang maksimal. Langkahnya adalah sebagai berikut:

1. Lepaskan semua bagian-bagian injektor.

2. Bersihkan semua bagian dari kotoran dan kerak yang menempel.

3. Pasangkan kembali semua bagian-bagian injector serta gunakan jarum tekan dan rumah jarum tekan baru.

4. Tambahkan shim atau atur baut pengatur tekanan untuk mencapai tekanan $320 \mathrm{~kg} / \mathrm{cm}^{2}$.

Berdasarkan alternatif pemecahan masalah yang telah dikemukakan, akhirnya peneliti mengambil beberapa pemecahan masalah yang dirasa cukup efektif, untuk kasus:

1. Timing injection (waktu pengabutan) yang tidak tepat, solusinya:

a. Melakukan overhaul pada fuel injection pump untuk membersihkan bagian-bagian yang kotor serta mengganti komponen yang rusak.

Proses overhaul memakan waktu yang lama. Pembersihan dilakukan mulai dari bagian yang besar hingga bagian terkecil. Perlu ketelitian dalam melakukan overhaul karena jika salah pada saat membongkar ataupun memasang, dapat mengakibatkan fuel injection pump tidak bekerja. Maka dari itu, pekerjaan ini harus direncanakan dengan baik agar hasilnya tidak efektif.

Keuntungan : Dengan overhaul pembersihan dapat dilakuakan seteliti mungkin dan terinci karena fuel injection pump dibongkar secara keseluruhan.

Kerugian : Pekerjaan ini memakan waktu yang lama, sehingga jika dilakukan dengan tidak terencana akan menjadi tidak efektif.

b. Mengatur ketebalan shim pada fuel injection pump untuk mendapatkan derajat pengabutan yang tepat

Mengatur derajat timing injction pada fuel injection pump dapat dilakukan dengan cara mengatur ketebalan shim-nya. Penambahan atau pengurangan ketebalan shim dilakukan untuk memajukan atau memundurkan waktu pengabutan sesuai dengan ketentuan dari instruction manual book.

Keuntungan : Derajat waktu pengabutan yang tepat akan didapatkan secara teliti dan berkesinambungan.

Kerugian : Dibutuhkan variasi ketebalan shim dan tenaga personal yang banyak dalam menyelesaikan pekerjaan.

c. Membersihkan saluran pipa bahan bakar (fuel oil pipe) pada fuel injection pump

Pembersihan saluran pipa bahan bakar pada sistem pengabutan bahan bakar dari endapan kotoran dapat dilakukan dengan cara flushing dengan solar untuk menghilangkan tempelan kerak-kerak yang telah mengeras.

Keuntungan : Membersihkan saluran pipa bahan bakar dapat memaksimalkan aliran dan tekanan bahan bakar.

Kerugian : Pekerjaan harus dilakukan seteliti mungkin kesalahan dalam membersihkan saluran pipa bahan bakar dapat mengakibatkan kebocoran.

2. Goresan pada jarum tekan injector (plunger), solusinya:

a. Melakukan lapping pada jarum tekan injector Goresan atau baret pada jarum tekan injector dapat mengakibatkan tidak sempurnanya pengabutan bahan bakar. Goresan yang masih dalam batas toleransi dapat diatasi dengan melakukan lapping dengan brasso untuk meminimalisasi goresan yang ada.

Keuntungan: Hasil tekanan pengabutan yang didapatkan mendekati titik sempurna.

Kerugian: Tekanan maksimal yang dihasilkan dari jarum tekan hasil lapping tidak dapat bertahan lama.

b. Mengganti jarum tekan (plunger) dan rumah jarum tekan injector

Tekanan pengabutan akan turun dari titik normal karena lolosnya kompresi bahan bakar 
melalui goresan yang ada pada jarum tekan. Pergantian jarum tekan dan rumah jarum tekan yang mengalami goresan serius harus dilakukan untuk mendapatkan kembali pengabutan bahan bakar yang sempurna.

Keuntungan : Tekanan pengabutan yang didapatkan mencapai titik sempurna dan bertahan lebih lama.

Kerugian : Pergantian suku cadang secara serentak mengakibatkan menipisnya persedian suku cadang yang ada jika sewaktu-waktu harus menghadapi situasi darurat.

\section{KESIMPULAN}

Setelah peneliti menguraikan beberapa permasalahan yang muncul serta pembahasan yang berkaitan dengan pengabutan bahan bakar pada diesel, maka dapat disimpulkan sebagai berikut :

1. Terlambatnya waktu pengabutan bahan bakar pada diesel generator nomor 2 disebabkan karena rendahnya suhu gas buang pada silinder nomor 1 dan 2. Hasil pengambilan tekanan Pmax menunjukkan tekanan yang tidak mencapai titik maksimal pada silinder nomor 1 dan 2 atau Pmax nya terlalu rendah.

2. Permasalahan pada fuel injektor (goresan pada jarum tekan atau plunger) disebabkan karena perbedaan temperatur gas buang yang sangat signifikan pada diesel generator nomor 2, termometer pada gas buang silinder nomor 4 dan 5 menunjukan angka diatas rata-rata sedangkan pada silinder lainnya yaitu nomor 1, 2, 3 dan 6 temperatur terlihat normal yaitu berkisar antara $3500 \mathrm{C}-3700 \mathrm{C}$.

Adapun saran yang peneliti berikan antara lain :

1. Overhaul secara menyeluruh pada fuel injection pump berguna untuk membersihkan bagian-bagian yang kotor serta mengatur ulang waktu pengabutan sesuai dengan rekomendasi manual book.

2. Pergantian jarum tekan injector harus dilakukan untuk mendapatkan pengabutan yang sempurna kedalam ruang bakar.

\section{DAFTAR PUSTAKA}

[1] Arismunandar, Wiranto. 2008. Motor Diesel Putaran Tinggi. Jakarta : Pradnya Paramita

[2] Arismunandar, Wiranto. 1988. Penggerak Mula Motor Bakar Torak. Bandung : Penerbit ITB
[3] Kuiken, Kees. 2008. Diesel Engines for Ship Propulsion and Power Plants. Onnen : The Netherlands

[4] Operation Instruction Manual (Maintenance), Daihatsu Diesel 6DK-20E

[5] Operation Instruction Manual (Operation), Daihatsu Diesel 6DK-20E

[6] Sukoco dan Zainal Arifin. 2008. Teknologi Motor Diesel. Bandung : Alfabeta 